\title{
GENDER DIFFERENCES IN DISAGREEMENT STRATEGIES IN ORAL ACADEMIC DISCOURSE
}

\author{
Andrei V. Achkasov \\ Herzen State Pedagogical University of Russia, Saint Petersburg, Russia \\ Yana V. Barsova \\ Herzen State Pedagogical University of Russia, Saint Petersburg, Russia
}

\begin{abstract}
The research aims to identify the gender differences in expressing disagreement in oral academic discourse. Examples containing explicit and implicit ways of expressing disagreement are collected through reading a corpus of texts chosen from the Michigan Corpus of Academic Spoken English (MICASE), including speech genres of seminar, discussion, defense of the dissertation and colloquium. Our study confirmed previous observations that utterances of explicit unmitigated disagreement or criticism are generally not typical of the American academic environment. The research findings reveal that both men and women tend to express disagreement explicitly using basic mitigation strategies. Unmitigated utterances with straightforward disagreement are infrequent and used mainly by teachers, which is most likely due to the other sociolinguistic variables apart from gender, and in particular by the status of speakers in teacher-student situations. Contrary to previous claims, men prefer the tactics of down-toning, represented by language patterns with the meaning of problematic certainty and subjectivity, as well as the use of lexical hedges. Female teachers recurrently use particular ways of implementing the tactics of mitigating implicit expression of disagreement, which may be specific of their individual styles. The research confirms that the distribution of particular language patterns across speakers should be taken into account when studying the gender aspects of communication.
\end{abstract}

Key words: gender, gender linguistics, academic discourse, disagreement, corpus linguistics.

Citation. Achkasov A.V., Barsova Ya.V. Gender Differences in Disagreement Strategies in Oral Academic Discourse. Vestnik Volgogradskogo gosudarstvennogo universiteta. Seriya 2. Yazykoznanie [Science Journal of Volgograd State University. Linguistics], 2020, vol. 19, no. 5, pp. 14-24. (in Russian). DOI: https://doi.org/10.15688/jvolsu2.2020.5.2

\section{ГЕНДЕРНЫЕ РАЗЛИЧИЯ ВЫРАЖЕНИЯ НЕСОГЛАСИЯ В УСТНОМ АКАДЕМИЧЕСКОМ ДИСКУРСЕ}

\section{Андрей Валентинович Ачкасов}

Российский государственный педагогический университет им. А.И. Герцена, г. Санкт-Петербург, Россия

\section{Яна Владимировна Барсова}

Российский государственный педагогический университет им. А.И. Герцена, г. Санкт-Петербург, Россия

Аннотация. Цель исследования состоит в выявлении гендерной специфики выражения несогласия в устном академическом дискурсе. Источником для отбора речевого материала послужил Мичиганский корпус устного академического английского языка (MICASE). Примеры, содержащие эксплицитные и имплицитные способы выражения несогласия, собраны методом сплошного чтения текстов, фиксирующих научное общение в жанрах семинара, дискуссии, защиты диссертации и коллоквиума. Установлено, что в устном академическом дискурсе женщин и мужчин преобладает эксплицитное выражение несогласия в сочетании 
с основными тактиками смягчения высказывания. Выражение прямого несогласия без использования тактик смягчения представлено незначительным количеством примеров в речи преподавателей, что обусловлено преимущественно негендерными социолингвистическими переменными, а именно статусом коммуникантов в ситуациях общения «преподаватель - студент». В речи мужчин предпочтение отдается тактике снижения категоричности, репрезентированной языковыми единицами с семантикой проблематической достоверности и субъективности, а также лексическими хеджами, что противоречит выводам, сделанным в исследованиях других ученых. Для речи женщин-преподавателей характерно регулярное использование конкретных приемов реализации тактик смягчения имплицитного выражения несогласия, что может иметь идиостилевой характер. Исследование подтверждает необходимость учитывать при анализе гендерного аспекта коммуникации характер дистрибуции языковых средств в речи конкретных коммуникантов.

Ключевые слова: гендер, гендерная лингвистика, академический дискурс, несогласие, корпусная лингвистика.

Цитирование. Ачкасов А. В., Барсова Я. В. Гендерные различия выражения несогласия в устном академическом дискурсе // Вестник Волгоградского государственного университета. Серия 2, Языкознание. 2020. - T. 19, № 5. - C. 14-24. - DOI: https://doi.org/10.15688/jvolsu2.2020.5.2

\section{Введение}

Настоящая работа находится в русле гендерных исследований, предполагающих выявление специфического набора языковых единиц, типичных стратегий и тактик, характерных для речи мужчин и женщин в ситуациях профессиональной коммуникации. Исследования, выполненные в этой парадигме, дают разные, а нередко противоположные результаты для разных типов профессионального дискурса. Так, М. Чавес считает стратегию речевого поведения женщин в академической коммуникации наставнической [Chavez, 2000]. В. Савицки, М. Келли и Д. Лингенфельтер пришли к выводу о том, что гендер не оказывает существенного влияния на речевое поведение участников конференций по компьютерным технологиям [Savicki, Kelley, Lingenfelter, 1996].

Выводы о значимости гендерного фактора в ситуации полемики и несогласия в академическом дискурсе противоречивы (см., например: [Кирилина, Маслова, 2009; Baker, 2014; Koczogh, 2012]). Х. Коцог утверждает, что женщины чаще выражают несогласие в научном стиле в эксплицитной форме, чем мужчины, используя при этом более экспрессивные средства [Koczogh, 2012]. А.В. Кирилина и Л.Н. Маслова в работе о гендерной специфике согласия и несогласия в устной научной дискуссии отмечают, что выбор женщинами прямых форм высказывания не приводит к прямой критике [Кирилина, Маслова, 2009]. П. Бейкер не находит в речи женщин каких-либо последовательных тенденций в выражении несогласия, обусловленных фактором гендера [Baker, 2014]. По мнению ряда лингвистов, в устной форме академического дискурса в целом преобладает коммуникативная стратегия неконфронтативности, а критика и несогласие принимают преимущественно косвенные, скрытые или смягченные формы [Кирилина, Маслова, 2009; Mauranen, 2002].

Противоречивость результатов указанных исследований может быть связана с различиями в интерпретациях ситуаций полемики и несогласия в академическом дискурсе. Вслед за Л.М. Гваджая [Гваджая, 2015], под коммуникативной ситуацией несогласия мы понимаем несогласие говорящего с адресатом, критику, иное мнение, мотивированные когнитивным противоречием участников общения и направленные на принятие одной из отстаиваемых позиций как верной.

Устный академический дискурс необходимо отграничить, с одной стороны, от других видов институционального и профессионального дискурса, а с другой - от письменного академического дискурса, отличающегося более жесткими конвенциями.

В лингвистике неоднократно отмечалось, что языковые средства, характерные для стилей речи, почти никогда напрямую не маркируют социальные категории. Стили речи и социальная категоризация опосредованы видами деятельности, отношениями, мнениями, конвенциональными формами поведения, отличающими этническую, социальную или профессиональную группу людей [Schleef, 2008]. 
В рамках академического дискурса как одного из видов институционального дискурса коммуниканты выступают как представители определенного социального института [Карасик, 2002]. Согласно мнению Е.И. Шейгал, институциональный дискурс осуществляется «в общественных институтах, общение в которых является составной частью их организации» [Шейгал, 2000, с. 43]. Академический дискурс в высших учебных заведениях отражает их цель - подготовку специалистов высокой квалификации [Зубкова, 2010], получение и трансляцию научного знания [Шилихина, 2013]. Устный академический дискурс - «устное интеллектуализированное общение с широкой аудиторией на темы специальности» [Скорикова, Орлов, 2017, с. 119]. Мы понимаем академический дискурс как разновидность институционального общения с целью передачи профессиональных знаний, объединяющего в себе все формы речевой деятельности, которые локализуются в коммуникативном пространстве высшего образования и науки.

Институциональные и профессиональные рамки, принятые в академическом дискурсе, накладывают определенные ограничения на используемые языковые средства и коммуникативные стратегии. Между устным и письменным видами академического дискурса существуют различия, обусловленные значительно большей близостью устного дискурса к разговорному языку. Вербальные особенности организации устной академической речи детерминируются фактором адресованности к конкретной аудитории в конкретный временной отрезок протекания речи, в условиях конкретной коммуникативной ситуации с учетом статуса коммуникантов, что не актуально в письменной форме сообщения научной информации. Как следствие, в процессе реализации коммуникативных стратегий и тактик, направленных на достижение той или иной коммуникативной цели в устном общении, речевое поведение говорящих может быть детерминировано различными факторами, в том числе гендером, и проявиться в предпочтении одних речевых приемов другим [Гриценко, 2005; Халеева, 2001; Tannen, 1996]. Основным внешним ограничением в устном академическом дискурсе становится необходи- мость действовать в рамках заданной социальной роли, определяемой конкретной ситуацией (лекция, семинар, выступление на конференции, защита диссертации и т. д.). Роль вносит в академический дискурс элемент ритуальности и в значительной степени детерминирует набор возможных речевых действий. К внутреннему ограничению относятся требования научного стиля, характеризующегося логической доказательностью, терминологичностью, стремлением к точности изложения фактов и т. д. В связи с этим индивидуальная речевая манера говорящих проявляется в профессиональной речи с меньшей интенсивностью, чем в неинституциональных типах дискурса.

\section{Материал и методы исследования}

Указанная выше полемичность изучения устного академического дискурса обусловила подход к отбору и анализу материала. Значительная часть исследований, посвященных гендерной вариативности в речи, выполнена с применением квантитативных методов, которые на основе формализованного поиска позволяют получить данные о количественном распределении языковых единиц и статистически значимых тенденциях в их употреблении. Значимая статистическая асимметрия в использовании тех или иных единиц позволяет интерпретировать их как маркеры гендерных речевых стилей. При таком подходе, вопервых, не всегда учитываются коммуникативные контексты употребления языковых единиц, во-вторых, не обеспечивается выявление типичных коммуникативных ситуаций и стратегий, поскольку выполняется только формализованный поиск.

Обнаружение коммуникативных ситуаций несогласия методом формализованного поиска типичных речевых маркеров несогласия, таких как отрицательное слово по, частица not, глагол disagree и т. п., оказалось непродуктивным, поэтому сбор материала осуществлялся методом сплошного чтения, с опорой на макроконтексты (смежные реплики коммуникантов).

Источником материала для исследования послужил Мичиганский корпус устного академического английского языка (Michigan 
Corpus of Academic Spoken English MICASE (https://quod.lib.umich.edu/cgi/c/corpus/ corpus? page $=$ home $; \mathrm{c}=$ micase $; \mathrm{cc}=$ micase д дата обращения: 20.02.2020). Корпус содержит более 1,8 млн словоупотреблений, охватывает период с 1997 по 2001 г. и включает образцы устной академической речи преподавателей и студентов Мичиганского университета (США). На основе корпуса MICASE был создан подкорпус, содержащий тексты четырех речевых жанров, которые предполагают диалогическую форму общения и отражают ситуации, провоцирующие открытую полемику. В подкорпус вошли 25 текстов, относящихся к речевым жанрам «семинар» (7 текстов), «дискуссия» (9 текстов), «защита диссертации» (4 текста) и «коллоквиум» (5 текстов). Общий объем подкорпуса составляет 300 тыс. словоупотреблений.

Методом сплошного чтения было отобрано 147 примеров выражения несогласия в рамках отдельного высказывания или группы смежных высказываний. Классификация материала проведена с учетом нескольких принципов.

Как показал анализ, несогласие, понимаемое нами в широком смысле (не только как отрицание пропозиции, содержащейся в высказывании адресата, но и как критика позиции собеседника и выражение иного мнения), может быть представлено эксплицитно при помощи формальных маркеров (лексические и грамматические средства) или имплицитно на уровне дискурса или конкретной коммуникативной ситуации. Отобранные примеры в соответствии с классификацией В.Н. Бондаренко [Бондаренко, 1983, с. 139] делим на два типа. В высказываниях первого типа несогласие выражено эксплицитно на морфологическом, синтаксическом или лексическом уровне при помощи отрицательных частиц, аффиксов, местоимений и наречий. В высказываниях второго типа несогласие выражено имплицитно, в них отсутствует грамматический или лексический показатель с соответствующим значением, поэтому фраза декодируется как содержащая несогласие или критику с опорой на контекст в границах нескольких сверхфразовых единств - реплик, которыми обмениваются участники коммуникации. В примерах второй группы несогласие реализовано на уровне дискурсивной ситуации, несчитываемой в поверхностной структуре предложения, либо выражено при помощи слов и словосочетаний с отрицательной семантикой (например, mistake, omission), риторических вопросов, восклицаний и т. д.

Еще одним принципом классификации высказываний стало наличие в них тактик смягчения критики с целью соответствия нормам рыечевой вежливости и успешного бесконфликтного взаимодействия в рамках институционального дискурса. В ходе анализа были выявлены четыре основные тактики, используемые участниками научной дискуссии при выражении несогласия или негативных оценок: тактика маскировки критики, тактика обоснования критики, тактика снижения категоричности высказывания и тактика одобрения (похвалы, положительной оценки). Bce перечисленные тактики реализуются в высказываниях как с эксплицитно, так и с имплицитно выраженными несогласием или критикой.

К основным средствам, которые применяются в тактике маскировки критики, относятся противительные союзы (but, yet), в начале высказывания передающие оттенок возражения; вводные слова и конструкции, указывающиена расхождение мнений коммуникантов; дополняющие реплики, интенция которых заключается в побуждении собеседника обосновать свою позицию; риторические и аффективные вопросы, задаваемые с целью выразить возражение, недоверие, критику, а не запросить сведения.

При использовании тактики обоснования критики высказывание сопровождается комментарием, призванным мотивировать несогласие, на что могут указывать причинно-следственные союзы (because, as, since, for).

В случае использования тактики снижения категоричности высказывания реплика содержит языковые единицы с семантикой проблематической достоверности, неуверенности, субъективности (модальные глаголы think, believe, guess, seem, suppose и др.; наречия со значением неуверенности probably, possibly, maybe; наречия меры и степени a little, a bit, somewhat; лексические маркеры - хеджи I mean, well, like), а также инициальные формулы, снижающие 
ультимативность высказывания (I can be wrong; I'm not sure; I'm not saying you're wrong и т. п.).

Тактика инициального одобрения предполагает выражение положительного отношения к точке зрения оппонента, частичное согласие с его мнением, в связи с чем высказывание дополняется компонентами с позитивной оценкой.

\section{Анализ материала}

В корпусе отобранных примеров реплики, содержащие эксплицитно или имплицитно выраженное несогласие, принадлежат 25 коммуникантам мужского пола и 23 коммуникантам женского пола, при этом 82 реплики принадлежат мужчинам и 65 - женщинам. Таким образом, в среднем на каждого коммуниканта мужского пола приходится 3,28 реплик, а на каждого коммуниканта женского пола $-2,82$ реплик. Количественное преимущество в высказывании критики и несогласия мужчинами объясняется тем, что в текстах речевого жанра защиты диссертации, в котором реализация полемического, дискуссионно- го начала проявилась с повышенной интенсивностью, отмечается аболютное преобладание говорящих мужского пола. Из перечня выделенных нами примеров 44 реплики (30\% от общего числа проанализированных реплик) были отобраны из текстов жанра «защита диссертации», при этом 41 из них принадлежит мужчинам и только 3 - женщинам (в связи с тем, что в составе диссертационного совета, лишь за несколькими исключениями, были представлены только мужчины).

Полученные в ходе анализа количественные данные об эксплицитном и имплицитном выражении несогласия, а также использовании различных тактик в речи мужчин и женщин обобщены в таблице.

Как женщины, так и мужчины выражают несогласие преимущественно эксплицитно (60\% и $68 \%$ соответственно). В таких высказываниях отрицается пропозиция реплики адресата при помощи отрицательного слова $n o$ или частицы $n o t$, присоединяемой к глагольным формам. Примерно в равной пропорции в речи женщин и мужчин представлены и примеры имплицитного выражения несогласия ( $40 \%$ и $32 \%$ соответственно).

Таблица. Количественные данные об эксплицитном и имплицитном выражении несогласия и использовании тактик смягчения несогласия в речи мужчин и женщин

Table. Distribution of cases of explicit and implicit disagreement and mitigation strategies in men's and women's speech

\begin{tabular}{|l|c|c|c|c|}
\hline \multirow{2}{*}{$\begin{array}{c}\text { Способы } \\
\text { выражения несогласия }\end{array}$} & $\begin{array}{c}\text { Количество } \\
\text { высказываний }\end{array}$ & $\begin{array}{c}\text { Доля от общего ко- } \\
\text { личества высказы- } \\
\text { ваний мужчин, }\end{array}$ & $\begin{array}{c}\text { Количество } \\
\text { высказываний }\end{array}$ & $\begin{array}{c}\text { Доля от общего ко- } \\
\text { личества высказы- } \\
\text { ваний женщин, \% }\end{array}$ \\
\hline $\begin{array}{l}\text { Эксплицитное выражение } \\
\text { несогласия / критики }\end{array}$ & 56 & 68 & 39 & 60 \\
\hline $\begin{array}{l}\text { Высказывания без тактик смяг- } \\
\text { чения несогласия }\end{array}$ & 11 & 13 & 10 & 15 \\
\hline Тактика маскировки критики & 10 & 12 & 4 & 6 \\
\hline Тактика обоснования критики & 4 & 5 & 5 & 34 \\
\hline $\begin{array}{l}\text { Тактика снижения категорич- } \\
\text { ности }\end{array}$ & 41 & 50 & 22 & 5 \\
\hline $\begin{array}{l}\text { Тактика инициальной похвалы, } \\
\text { одобрения }\end{array}$ & 6 & 7 & 26 & 40 \\
\hline $\begin{array}{l}\text { Имплицитное выражение не- } \\
\text { согласия / критики }\end{array}$ & 26 & 32 & 26 & 40 \\
\hline Тактика маскировки критики & 26 & 32 & - & - \\
\hline Тактика обоснования критики & 2 & 2 & 12 & 18 \\
\hline $\begin{array}{l}\text { Тактика снижения категорич- } \\
\text { ности }\end{array}$ & 20 & 24 & 3 & 5 \\
\hline $\begin{array}{l}\text { Тактика инициальной похвалы, } \\
\text { одобрения }\end{array}$ & 3 & 4 & & \\
\hline
\end{tabular}


Доля прямого выражения несогласия без применения тактик смягчения в речи мужчин и женщин составляет соответственно $13 \%$ и $15 \%$ от общего количества высказываний в корпусе примеров. Предпочтений в употреблении формальных показателей несогласия для мужчин и женщин не выявлено. Следует отметить, что использование прямого несогласия без смягчения связано со статусом коммуникантов и отмечено преимущественно в речи преподавателей:

(1) [преподаватель-женщина] Speaker 1: oh you, you have a kinetochore.

[студент] Speaker 6: but, it's on his side though. [преподаватель-женщина] Speaker 1: no your kinetochore is here. it's it's over here;

(2) [студент] Speaker 2: but he they did at one time, were able to hear confessions but that's not the same thing as being a priest like

[преподаватель-мужчина] Speaker 1: i don't Francis doesn't hear confessions. he had, he had he has no, Francis had no authority to absolve sins or to do what a priest did.

Выражение прямого и имплицитного несогласия в сочетании с тактиками смягчения имеет ряд выраженных тенденций в речи мужчин и женщин и может быть проанализировано отдельно для каждой группы.

В речи женщин предпочтение отдается двум тактикам смягчения несогласия - маскировки критики (40 \% от общего числа реплик) и снижения категоричности (18\% от общего числа реплик). В 16 примерах используется сразу несколько тактик, чаще всего сочетание косвенной критики и лексических средств снижения категоричности:

(3) Speaker 10: i have a question regarding like the label of feminist um, as a student in the nuclear engineering department and working in the same clinical department as Jean $<\ldots>$

Speaker 8: yeah but i think it's i think it's a little bit more complicated than that. $i$ just finished reading a book that discussed that $<\ldots>$

В приведенном примере (3) вводная конструкция с противительным союзом but включает глагол think с семантикой субъективного отношения к высказываемой информации, а основная часть высказывания, содержащая структуру со значением несогласия (it's more complicated than that, где референт местоимения that - высказанное адресатом мнение), сопровождается наречием степени a little bit, что также смягчает категоричность высказывания.

В другом примере модератор дискуссии разворачивает полемику с участником обсуждения, используя широкий набор средств смягчения несогласия:

(4) Speaker 2: well you need something to do. you go crazy when you like stagnate and have nothing to do.

Speaker 1: i think that's, that's i mean there's definitely um, there's definitely, some truth to this, i mean, i'm not saying you're wrong, but on the other hand think about um, did you ever read, um any novels by Jane Austin say or, see any of the movies?

Модератор употребляет модальные глаголы со значением мнения (think, mean) и формулу инициального одобрения с усилительным наречием уверенности definitely, признавая частично правоту говорящего (there's definitely some truth to this). В то же время противительный союз but вводит перформатив, стимулирующий дискуссию (but on the other hand think about).

В речи женщин значительно реже, чем в речи мужчин используются тактики обоснования критики ( $8 \%$ от общего количества высказываний) и инициальной похвалы (5 \% от общего количества высказываний). Тенденция к применению этой тактики прослеживается в речи только одной из коммуникантов-женщин:

(5) Speakers: the horizon?

Speaker 1: nope and that's because the celestial equator is about here so farther up in the sky;

(6) Speaker 1: < ..> if we went out, and it's, six or seven P-M so just after it's getting dark, if we look over here to the southwestern part of the sky, about here, there will be a very, bright object, that's larger than any star that you'll see in the sky, any guesses on what that would be? Speaker 4: Jupiter

Speaker 1: nope not Jupiter [S4: oh ] good guess Speaker 2: Saturn?

Speaker 1: not Saturn, good guess.

Результаты анализа показали, что в речи отдельных коммуникантов-женщин наблюда- 
ется тенденция к использованию определенных приемов реализации тактик смягчения имплицитного выражения несогласия. Так, одна из преподавателей вместо прямого выражения несогласия последовательно прибегает к повторению вопроса до тех пор, пока не получает требуемого ответа:

(7) Speaker $1:<\ldots>$ we think, s- we need some sort of central authority right? cuz we want what? Speaker 5: we want, representation.

Speaker 1: what do we want? what do we want from the government?

Speakers: collective goods;

(8) Speaker 1: what does a stop sign mean? Speaker-f: to stop.

Speaker 1: what does a stop sign mean?

В речи другого преподавателя несогласие выражается при помощи косвенных вопросов, которые одновременно выступают в качестве стимулирующих реплик, побуждающих студентов к самокоррекции:

(9) Speaker 4: crossing over, can occur i put meiosis one and two

Speaker 1: wanna take something back?

Speaker 4: um, not meiosis two;

(10) Speaker 10: meiosis is, haploid. right? $<$ LAUGH $>$ (xx)

Speaker 10: anyone wanna help her out?

В других случаях имплицитное несогласие выражено на лексическом уровне при помощи единиц с семантикой отрицания и негативной оценки либо единиц, контекстуально противопоставленных по значению единицам, использованным в высказывании собеседника.

(11) Speaker 4: you're s- producing the same amount $<\ldots>$

Speaker 3: yeah but in terms of the amount of people that are involved in producing and benefitting from this activity, it's much more reduced $<\ldots>$

В примере (11) противоречие точек зрения говорящих локализовано в словосочетании the same amount и противопоставленного ему прилагательного reduced, сопровождаемого в рамках фразового единства частицей yeah и противительным союзом but.
Как уже было отмечено, статистически способы выражения несогласия в речи мужчин в целом коррелируют со способами выражения несогласия в речи женщин. При имплицитно выраженном несогласии в речи мужчин тактика маскировки критики используется преимущественно в сочетании с тактикой снижения категоричности, реализованной при помощи различных лексических средств (20 из 26 высказываний). Например:

(12) Speaker 1: i think you could make it, somewhat broader than that. i think you could say, that after fourteen, twenty-five or something like that, that that... um

Критическое замечание в адрес автора доклада (you could make it somewhat broader than that) содержит модальный глагол can в сослагательном наклонении, что придает высказыванию рекомендательный характер, а также маркер предположения I think и наречие-диминутив somewhat:

Наименее распространенными тактиками смягчения критики в речи мужчин являются тактики обоснования критики (7 \% от общего количества высказываний мужчин) и инициальной похвалы (11 \% от общего количества высказываний).

Особенностью реализации критики и несогласия в речи мужчин является очевидное предпочтение тактики снижения категоричности высказывания (61 пример, 74 \% от общего количества высказываний). В репликах мужчин используются конструкции с семантикой неуверенности, подчеркнуто субъективного отношения коммуниканта к сообщаемой им информации, снижения ответственности за высказываемое и уменьшения категоричности. Следует также отметить регулярное употребление в речи мужчин дискурсивных маркеров I mean, right, okay, really и маркер хеджинга well. Одно высказывание может содержать целый ряд средств хеджирования, уменьшения степени описываемого признака либо оценки, а также снижения категоричности:

(13) Speaker 2: i was concerned, with other's reaction and $i$, could feel... i mean i didn't, mean that, Western thinking is better, in all sense it's better for doing modern science $<\ldots>$

S5: well $i$ i th- no i think it's fairly clear Western thinking is better if you're gonna do science but 
that doesn't mean, that it's better, in general. there_it's it's not as good for other things;

(14) Speaker 2: so $<\ldots>$ i mean, seems to me that there's a fun- there's a more fundamental problem, [S1: mhm ] that, i don't hear you articulating $<\ldots>$ i don't believe that, i'm not sure that you've really, done your job in looking at the various ways that you could make the decision without having proof.

\section{Результаты и обсуждение}

Статистическое расхождение в эксплицитном и имплицитном выражении несогласия в речи мужчин и женщин составляет $8 \%$. Учитывая объем корпуса примеров, данное расхождение нельзя интерпретировать как значимое. Внутри указанных групп примеров не выявлено выраженной тенденции распределения эксплицитного и имплицитного выражения несогласия в зависимости от статусов коммуникантов или речевых жанров. Можно предположить, что использование той или иной формы несогласия мотивировано типичными прагматическими задачами коммуникантов, которые могут быть классифицированы только с учетом широкого контекста, что не входило в задачи настоящего исследования. Полученные результаты не подтверждают высказывавшийся исследователями тезис о тяготении женщин к уклончивости в выражении своей позиции в профессиональной коммуникации, и в частности к предпочтению имплицитной формы выражения критики и несогласия [Coates, 2004].

Проведенный анализ в целом подтверждает наблюдения А. Мауранен, согласно которым эксплицитное выражение несогласия или критики без употребления средств смягчения нехарактерно для коммуникации в американской академической среде [Mauranen, 2002]. Относительно небольшой подкорпус примеров использования прямого несогласия без каких-либо тактик смягчения не позволил выявить специфических прагматических условий или тенденции в употреблении формальных показателей несогласия для мужчин и женщин. Применение указанного способа выражения несогласия определяется в первую очередь статусом коммуникантов в ситуации «преподаватель - студент».
Наиболее статистически значимое расхождение для мужчин и женщин установлено в использовании тактики снижения категоричности при эксплицитном выражении несогласия (50\% и $34 \%$ соответственно) и в меньшей степени - для имплицитного выражения несогласия (24\% и $19 \%$ соответственно). Хотя в общем объеме высказываний женщин тактика снижения категоричности также занимает существенное место (51 \% от общего числа реплик), мужчины не только чаще применяют эту тактику, но и совмещают ее с тактикой маскировки критики, регулярным использованием типичного набора дискурсивных маркеров и конструкций со значением проблематической достоверности и сомнения, призванных смягчить выражение несогласия или критики даже в тех случаях, когда они реализованы имплицитно. Таким образом, проведенный анализ не подтверждает выдвинутого Р. Лакоффом и другими исследователями [Lakoff, 2004; Mirzapour, 2016; Rezaee, Aghagolzadeh, Birjandi, 2015; Rosanti, Jaelani, 2016] предположения о том, что женщины склонны чаще использовать средства хеджирования и другие «семантически пустые» единицы, способствующие выстраиванию непрямой коммуникации и солидаризации с собеседником.

Мужчины чаще, чем женщины, применяют тактику маскировки критики при эксплицитном выражении несогласия, в то время как женщины используют эту тактику чаще при имплицитном выражении несогласия. Статистическая разница составляет $6 \%$ и $8 \%$ соответственно, а распределение количества примеров реализации указанной тактики между эксплицитным и имлицитным выражением несогласия является пропорциональным для мужчин и женщин. Учитывая полученные нами результаты, нет оснований утверждать, что установленные различия репрезентируют устойчивую тенденцию. Сказанное актуально и для статистических различий, выделенных для других тактик смягчения несогласия.

В ходе анализа широких контекстов было установлено, что в речи отдельных женщин-преподавателей регулярны такие приемы реализации тактик смягчения имплицитного выражения несогласия, как использование косвенных вопросов, побуждающих студентов к самокоррекции, 
или повторение вопроса вместо прямого выражения несогласия. В речи мужчин указанная тенденция не обнаружена. Выделенный набор приемов реализации различных тактик может иметь идиостилевой характер, не связанный с гендерными характеристиками речи. Вместе с тем, так как тенденция, выявленная на конкретном корпусе текстов, свойственна именно речи женщин, она заслуживает дальнейшего изучения в гендерном аспекте.

\section{Выводы}

В академической устной речи преобладает эксплицитное выражение несогласия в сочетании с различными тактиками смягчения категоричности высказывания. Выражение прямого несогласия без использования тактик смягчения составляет не более $15 \%$ от общего количества примеров, что коррелирует с результатами других исследований. Значимых статистических различий для речи мужчин и женщин в этом аспекте анализа не установлено, что не коррелирует с данными других исследований, согласно которым в научной коммуникации женщины тяготеют к имплицитной форме выражения критики и несогласия.

Можно утверждать, что в речи мужчин чаще используется тактика снижения категоричности как при эксплицитном, так и при имплицитном выражении несогласия. Высказывания мужчин, реализующие указанную тактику, характеризуются разнообразием лексических средств смягчения несогласия, что не подтверждает высказывавшуюся ранее гипотезу о преобладании таких средств в речи женщин. Данная тенденция характерна для всех исследованных нами жанров речи и не связана со статусом коммуникантов или типичными прагматическими контекстами.

Для речи женщин-преподавателей характерно регулярное применение определенных приемов реализации тактик смягчения имплицитного выражения несогласия, что может иметь идиостилевой характер. Так, достаточно частотный в корпусе высказываний женщин прием маскировки несогласия в форме риторического вопроса или повторения вопроса регулярно используется в речи только одного говорящего, на которого и приходится большин- ство реплик с данным приемом. Из сказанного следует, что данные о специфике дистрибуции тех или иных языковых единиц и тенденций их употребления в речи конкретных коммуникантов не всегда могут быть экстраполированы на всю группу.

\section{СПИСОК ЛИТЕРАТУРЫ}

Бондаренко В. Н., 1983. Отрицание как логико-грамматическая категория. М. : Наука. 212 с.

Гваджая Л. М., 2015. Полемичность как конститутивный признак текста и средства ее реализации // Вестник Воронежского государственного университета. Серия: Лингвистика и межкультурная коммуникация. № 1. С. 26-28.

Гриценко Е. С., 2005. Язык. Гендер. Дискурс. Н. Новгород : Изд-во ННГУ им. Н.И. Лобачевского. $267 \mathrm{c}$.

Зубкова Я. В., 2010. Признак институциональности в академическом дискурсе // Вестник Волгоградского государственного университета. Серия 2, Языкознание. № 2 (12). С. 84-89.

Карасик В. И., 2002. Язык социального статуса. М. : Гнозис. 333 с.

Кирилина А. В., Маслова Л. Н., 2009. Устная научная дискуссия: взаимосвязь конструирования гендера и статуса компетентного лица // Пол. Гендер. Культура. Немецкие и русские исследования $=$ Sex. Gender. Kultur. Deutsche und russische Forschungen / под ред. Э. Шоре, К. Хайдер, Г. Зверевой. М. : РГТУ. С. 231-260.

Скорикова Т. П., Орлов Е. А., 2017. Жанровые особенности устной научной коммуникации: концепция лингвистического описания // Beстник СВФУ. № 5 (61). С. 117-128.

Халеева И. И., 2001. Гендер в теории и практике обучения межъязыковой коммуникации // Гендер: язык, культура, коммуникация : докл. І Междунар. конф. (Москва, 22-23 нояб. 2001 г.). М. : МГЛУ. С. 7-11.

Шейгал Е. И., 2000. Семиотика политического дискурса. М. ; Волгоград : Перемена. 368 с.

Шилихина К. М., 2013. Ирония в академическом дискурсе // Вестник ВГУ. Филология. № 1 . C. 115-118.

Baker P., 2014. Using Corpora to Analyze Gender. L. : Bloomsbury Academic. 240 p.

Chavez M., 2000. Gender in the Language Classroom. Boston : McGraw-Hill Education. 264 p.

Coates J., 2004. Women, Men and Language. L. : Routledge. 264 p.

Koczogh H. V., 2012. The Role of Gender in Verbal Disagreement: A Study of Disagreement Strategies Employed by Hungarian Undergraduate Students 
// Gender Studies. Vol. 11, № 1. P. 233-244. DOI:

10.2478/V10320-012-0042-5.

Lakoff R., 2004. Language and Woman's Place: Text and Commentaries. Oxford : Oxford University Press. 328 p.

Mauranen A., 2002. “One Thing I'd Like to Clarify...”. Observations of Academic Speaking // Helsinki English Studies. Vol. 2. P. 1-10.

Mirzapour F., 2016. Gender Differences in the Use of Hedges and First Person Pronouns in Research Articles of Applied Linguistics and Chemistry // International Journal of Applied Linguistics \& English Literature. Vol. 5, № 6. P. 166-173. DOI: 10.7575/aiac.ijalel.v.5n.6p.166.

Rezaee M., Aghagolzadeh F., Birjandi P., 2015. The Effect of Lecturers' Gender on the Use of Discourse Markers // International Journal of Research Studies in Language Learning. Vol. 4, iss. 2. P. 69-87. DOI: 10.5861/ijrsll.2014.900.

Rosanti E. D., Jaelani A., 2016. The Use of Lexical Hedges in Spoken Language by Female and Male Students // Electronic Journals of UIKA Bogor. Vol. 16, № 1. P. 29-39.

Savicki V., Kelley M., Lingenfelter D., 1996. Gender, Group Composition and Task Type in Small Task Groups Using Computer Mediated Communication // Computers in Human Behavior. Vol. 2. P. 549-565. DOI: 10.1016/S07475632(96)00024-6.

Schleef E., 2008. Gender and Academic Discourse: Global Restrictions and Local Possibilities // Language in Society. Vol. 37, iss. 4. P. 515-538. DOI: $10.1017 / \mathrm{S} 0047404508080755$.

Tannen D., 1996. Gender \& Discourse. Oxford : Oxford University Press. 240 p.

\section{REFERENCES}

Bondarenko V.N., 1983. Otritsanie kak logikogrammaticheskaya kategoriya [Negation as a Logical and Grammatical Category]. Moscow, Nauka Publ. 212 p.

Gvadzhaya L.M., 2015. Polemichnost kak konstitutivnyy priznak teksta i sredstva ee realizatsii [Polemicity as a Constitutive Attribute of the Text and Means of Its Implementation]. Vestnik Voronezhskogo gosudarstvennogo universiteta. Seriya: Lingvistika $i$ mezhkulturnaja kommunikatsiya [VSU Philological Review. Series: Linguistics and Intercultural Communication], no. 1, pp. 26-28.

Gritsenko E.S., 2005. Yazyk. Gender. Diskurs [Language. Gender. Discourse]. Nizhniy Novgorod, Izd-vo NNGU im. N.I. Lobachevskogo. 267 p.

Zubkova Y.V., 2010. Priznak institutsionalnosti v akademicheskom diskurse [Features of
Institutionalism in Academic Discourse]. Vestnik Volgogradskogo gosudarstvennogo universiteta. Seriya 2, Yazykoznanie [Science Journal of Volgograd State University. Linguistics], no. 2 (12), pp. 84-89.

Karasik V.I., 2002. Yazyk sotsialnogo statusa [Language of Social Status]. Moscow, Gnozis Publ. 333 p.

Kirilina A.V., Maslova L.N., 2009. Ustnaya nauchnaya diskussiya: vzaimosvyaz konstruirovaniya gendera i statusa kompetentnogo litsa [Oral Academic Discussion: The Relationship Between Gender and Role Competencies]. Cheaure E., Heyder C., Zvereva G., eds. Pol. Gender. Kultura. Nemetskie i russkie issledovaniya $=$ Sex. Gender. Kultur. Deutsche und russische Forschungen [Sex. Gender. Culture. German and Russian Studies]. Moscow, RGTU, pp. 231-260.

Skorikova T.P., Orlov Y.A., 2017. Zhanrovye osobennosti ustnoy nauchnoy kommunikatsii: konceptsiya lingvisticheskogo opisaniya [Genre Features of Spoken Academic Communication: The Concept of Linguistic Description]. Vestnik SVFU [SVFU Review], no. 5 (61), pp. 117-128.

Khaleeva I.I., 2001. Gender v teorii i praktike obucheniya mezhyazykovoy kommunikatsii [Gender in the Theory and Practice of Teaching Interlanguage Communication]. Gender: yazyk, kultura, kommunikatsiya: dokl. I Mezhdunar. konf. (Moskva, 22-23 noyab. 2001 g.) [Gender: Language, Culture, Communication. Proceedings of the 1st International Conference (Moscow, November 22-23, 2001)]. Moscow, MGLU, pp. 7-11.

Sheygal E.I., 2000. Semiotika politicheskogo diskursa [Semiotics of Political Discourse]. Moscow, Volgograd, Peremena Publ. 368 p.

Shilikhina K.M., 2013. Ironiya v akademicheskom diskurse [Irony in Academic Discourse]. Vestnik $V G U$. Filologiya [VGU Philological Review], no. 1, pp. 115-118.

Baker P., 2014. Using Corpora to Analyze Gender. London, Bloomsbury Academic. 240 p.

Chavez M., 2000. Gender in the Language Classroom. Boston, McGraw-Hill Education. 264 p.

Coates J., 2004. Women, Men and Language. London, Routledge. 264 p.

Koczogh H.V., 2012. The Role of Gender in Verbal Disagreement: A Study of Disagreement Strategies Employed by Hungarian Undergraduate Students. Gender Studies, vol. 11, no 1, pp. 233-244. DOI: 10.2478/V10320012-0042-5.

Lakoff R., 2004. Language and Woman's Place: Text and Commentaries. Oxford, Oxford University Press. 328 p. 


\section{ГЛАВНАЯ ТЕМА НОМЕРА}

Mauranen A., 2002. "One Thing I'd Like to Clarify...”. Observations of Academic Speaking. Helsinki English Studies, vol. 2, pp. 1-10.

Mirzapour F., 2016. Gender Differences in the Use of Hedges and First Person Pronouns in Research Articles of Applied Linguistics and Chemistry. International Journal of Applied Linguistics \& English Literature, vol. 5, no. 6, pp. 166-173. DOI: 10.7575/aiac.ijalel.v.5n.6p.166.

Rezaee M., Aghagolzadeh F., Birjandi P., 2015. The Effect of Lecturers' Gender on the Use of Discourse Markers. International Journal of Research Studies in Language Learning, vol. 4, iss. 2, pp. 69-87. DOI: 10.5861/ ijrsll.2014.900.
Rosanti E.D., Jaelani A., 2016. The Use of Lexical Hedges in Spoken Language by Female and Male Students. Electronic Journals of UIKA Bogor, vol. 16, no. 1, pp. 29-39.

Savicki V., Kelley M., Lingenfelter D., 1996. Gender, Group Composition and Task Type in Small Task Groups Using Computer Mediated Communication. Computers in Human Behavior, vol. 2, pp. 549565. DOI: 10.1016/S0747-5632(96)00024-6.

Schleef E., 2008. Gender and Academic Discourse: Global Restrictions and Local Possibilities. Language in Society, vol. 37, iss. 4, pp. 515-538. DOI: $10.1017 / \mathrm{S} 0047404508080755$.

Tannen D., 1996. Gender \& Discourse. Oxford, Oxford University Press. 240 p.

\section{Information About the Authors}

Andrei V.Achkasov, Doctor of Sciences (Philology), Professor, Director, Institute of Foreign Languages, Head of the Translation Department, Herzen State Pedagogical University of Russia, Reki Moyki Emb., 48, 191186 Saint Petersburg, Russia, avachkasov@herzen.spb.ru, https://orcid.org/0000-0002-7637-4960

Yana V. Barsova, Postgraduate Student, Department of English Philology, Herzen State Pedagogical University of Russia, Reki Moyki Emb., 48, 191186 Saint Petersburg, Russia, yanakhromenko@yandex.ru, https://orcid.org/0000-0002-8269-0695

\section{Информация об авторах}

Андрей Валентинович Ачкасов, доктор филологических наук, профессор, директор института иностранных языков, заведующий кафедрой перевода, Российский государственный педагогический университет им. А.И. Герцена, Набережная реки Мойки, 48, 191186 г. Санкт-Петербург, Россия, avachkasov@herzen.spb.ru, https://orcid.org/0000-0002-7637-4960

Яна Владимировна Барсова, аспирант кафедры английской филологии, Российский государственный педагогический университет им. А.И. Герцена, Набережная реки Мойки, 48, 191186 г. Санкт-Петербург, Россия, yanakhromenko@yandex.ru, https://orcid.org/0000-0002-8269-0695 